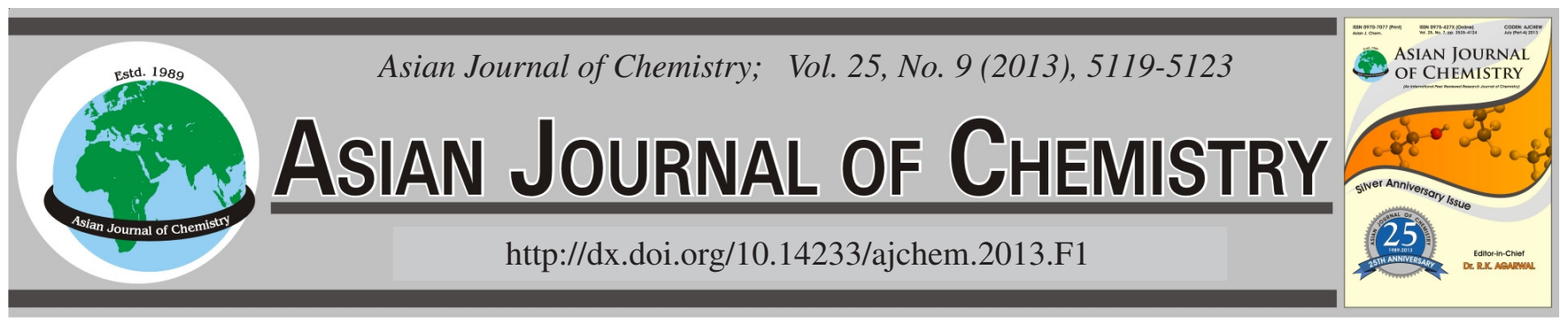

\title{
REVIEW
}

\section{Silane Effects on in-Rubber Silica Dispersion and Silica Structure $\left(\alpha_{\mathrm{F}}\right) \dagger$}

\author{
KWANG-JEA KIM
}

Dong Ah Tire and Rubber Co. Ltd., Gyeongnam 626-110, Republic of Korea

Corresponding author: Fax: +82 55 3882523; Tel: +82 55 3707959; E-mail: kkim@dongahtire.co.kr

\begin{abstract}
The degree of silica dispersion in a rubber matrix is an important issue in the rubber industry because silica agglomerates in rubber compounds are difficult to disperse compared to carbon black due to the polar characteristics of the silica surface. Considerable effort has been made to improve the degree of silica dispersion, such as the use of bifunctional organosilane, intermesh rotor type mixer, milling technique, etc. Wolff and his coworkers introduced the in-rubber filler structure $\left(\alpha_{\mathrm{F}}\right)$ for quantitative measurements of the filler structure. This paper reviews his research on the in-rubber structure of carbon black and silica and reports our recent results on silane-treated silica.

Key Words: In-rubber silica structure $\left(\alpha_{\mathrm{F}}\right)$, Bifunctional silane, Silica, Carbon black.
\end{abstract}

\section{INTRODUCTION}

Currently most major green tire tread manufacturing companies use intermesh type rotor mixers for the mechanical dispersion of silica particles in rubber compounds. Other efforts to improve silica dispersions aim to increase the compatibility between the silica surface and rubber chain, which involves the use of chemicals, such as bis-(3-triethoxysilylpropyl) tetrasulfane (TESPT) and bis-(3-triethoxysilylpropyl)disulfane (TESPD), which are well-known organo bifunctional silanes in the market. The addition of silane into silica filled rubber compound reduces the viscosity of the compound, which results in improved processability of the compound. This also results in a chemically-bonded silane-silica structure, which reduces the polar characteristics of the silica surface and improves the dispersion of silica particles. The silane treatment of a silica surface should clearly affect the structure of silica in rubber.

The structure of the filler can be presented in several ways, such as Wolff's in-rubber filler structure $\left(\alpha_{\mathrm{F}}\right)^{1-5}$, Payne effect ${ }^{6,7}$, etc. Wolff expressed $\alpha_{\mathrm{F}}$, as the slope derived from the ratio between the increase in rheometer torque of the filled compound $\left(\mathrm{D}_{\max }-\mathrm{D}_{\min }\right)$ and that of the unfilled compound $\left(\mathrm{D}_{\max }^{\mathrm{o}}-\mathrm{D}^{\mathrm{o}}{ }_{\text {min }}\right)$, which is directly proportional to the filler loading, as expressed in eqn. 1 :

$$
\frac{\mathrm{D}_{\text {max }}-\mathrm{D}_{\text {min }}}{\mathrm{D}_{\text {max }}^{\mathrm{o}}-\mathrm{D}_{\text {min }}^{\mathrm{o}}}-1=\alpha_{\mathrm{F}} \frac{\mathrm{m}_{\mathrm{F}}}{\mathrm{m}_{\mathrm{P}}}
$$

where $\alpha_{\mathrm{F}}$ is the in-rubber structure of the filler, $\mathrm{D}^{\circ}{ }_{\text {max }}-\mathrm{D}^{\circ}{ }_{\text {min }}$ is the torque difference of the unfilled compound, $\mathrm{D}_{\max }-\mathrm{D}_{\min }$ is the torque difference of the filled compound, $\mathrm{m}_{\mathrm{F}} / \mathrm{m}_{\mathrm{P}}$ is the filler to polymer weight ratio. Wolff et al. ${ }^{4,5}$ reported that the $\alpha_{\mathrm{F}}$ was constant over the entire range of carbon black (BET $140 \mathrm{~m}^{2} / \mathrm{g}$ ) filled in NR and NBR systems. On the other hand, in the case of a silica (BET $134 \mathrm{~m}^{2} / \mathrm{g}$ ) filled system, $\alpha_{\mathrm{F}}$ increased with increasing filler concentration. Their research focused mainly on the filler-filler interaction in rubber compounds.

Since Rauline $\mathrm{e}^{8,9}$ presented the use of a silica combination with TESPT for practical 'green tire' applications, there have been many studies on silane-modified silica rubber compounds in the tire tread compound. On the other hand, they focused mainly on the effects of the silica reinforcement ${ }^{10}$, silica dispersion ${ }^{11-15}$, moisture/temperature effects on coupling with silane $^{16-18}$, accelerator effects on the cure properties ${ }^{19,20}$, effects of polymer blends ${ }^{21-24}$ etc.

Silica consists mainly of silicon-oxygen ( $=\mathrm{Si}-\mathrm{O}-)$ bonds with hydroxyl groups (-OH) on silica surface, whereas carbon black (CB) consists mainly of carbon-carbon single and double bonds ( $\equiv \mathrm{C}-\mathrm{C} \equiv,=\mathrm{C}=\mathrm{C}=$ ). Silica particles exhibit a strong silicasilica interaction owing to its polar $\left(\mathrm{Si}^{+\delta}-\mathrm{O}^{-\delta}\right)$ character due to differences in electro negativity between $\mathrm{Si}$ (3.5) and $\mathrm{O}$ (1.9). In contrast, carbon black shows a weak $\mathrm{C}=\mathrm{C}$ interaction due to the presence of a $\pi$ - $\pi$ bond, thereby showing good compatibility with rubber chains, which contain a double bond. The 
$\pi-\pi$ bonds and/or oxygen on the carbon black surface interact with double bonds $(\pi-\pi)$ in the rubber chain, which shows good compatibility with the rubber chain. Therefore, the dispersion of carbon black is better than that of silica in the rubber matrix. On the other hand, modification of the silica surface with silanes, particularly with bifunctional organosilanes, such as TESPT and TESPD, assists in the dispersion of silica agglomerates in the rubber chain ${ }^{14,25-28}$. The chemical reaction between silica and silane as well as silane and rubber alters the network of the rubber matrix ${ }^{28-30}$. Hence, the filler network constant $\alpha_{F}$ of silane-modified silica is different from carbon black filled systems. This makes an interpretation of the in-rubber structure of the modified silica system more difficult. Few studies have examined in-rubber structure of silanemodified silica since Wolff's presentation at the Charles Goodyear Medal award in his 1996 presentation $^{3}$.

This paper reviews Wolff's in-rubber structure of the filler $\alpha_{\mathrm{F}}$ and compared their results with the results of other researchers including this laboratory ${ }^{31,32}$.

SBR/CB sulfur cure system ${ }^{33-37}$ : Fig. 1 shows the $\Delta$ torque $\left(D_{\max }-D_{\min }\right)$ relationship with the carbon black (N330) loading at constant concentrations of curing agent in the SBR compound with various sulfur levels. This gives straight lines with different slopes, whose extensions intersect in a common point on the $\mathrm{X}$-axis.

A linear correlation was observed between $\Delta$ torque $\left(\mathrm{D}_{\max }-\mathrm{D}_{\min }\right)$ and the carbon black loading at a constant concentration of accelerator (CBS).

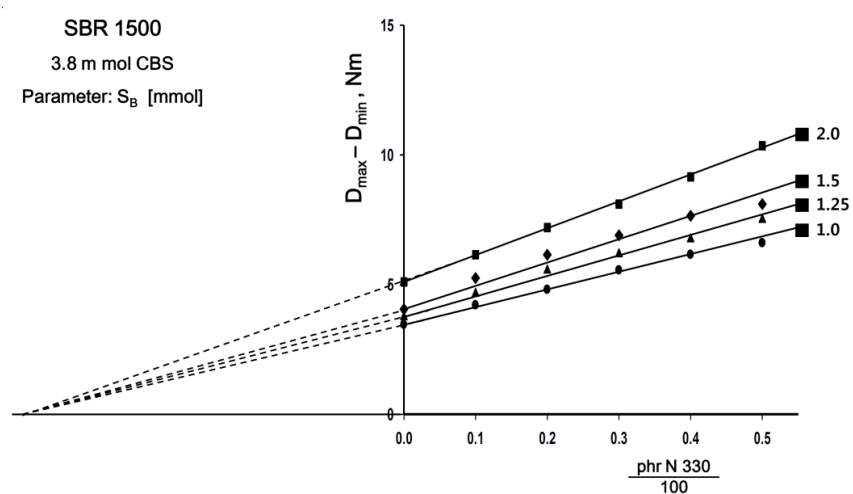

Fig. 1. $\Delta$ Torque $\left(\mathrm{D}_{\max }-\mathrm{D}_{\min }\right)$ vs. $\mathrm{CB}$ loading of the $\mathrm{SBR}$ compound with various sulfur levels at a constant accelerator concentration/redraw from the work of Wolff ${ }^{3}$

SBR/Silica sulfur cure system ${ }^{38,39}$ : Fig. 2 shows the $\Delta$ torque $\left(D_{\max }-D_{\min }\right)$ relationship with silica $\left(130 \mathrm{~m}^{2} / \mathrm{g}\right)$ loading at constant concentrations of curing agent in the SBR compound with various sulfur levels. This does not give straight lines due to interference with sulfur.

No linear correlations were observed between $\Delta$ torque $\left(\mathrm{D}_{\max }-\mathrm{D}_{\min }\right)$ and the silica loading at constant concentrations of curing agent.

SBR/Silica peroxide cure system ${ }^{39}$ : Silica does not interfere with the reaction mechanism of dicumyl peroxide curing, which has a radical reaction mechanism. At a constant dicumyl peroxide concentration, there was a linear correlation between $\Delta$ torque $\left(\mathrm{D}_{\max }-\mathrm{D}_{\min }\right)$ and silica $\left(175 \mathrm{~m}^{2} / \mathrm{g}\right)$ loading. Fig. 3 shows straight lines with different dicumyl peroxide concentrations, which intersect at a common point on the $\mathrm{x}$-axis. The slope of the SBR/Silica compound increases with increasing dicumyl peroxide concentration.

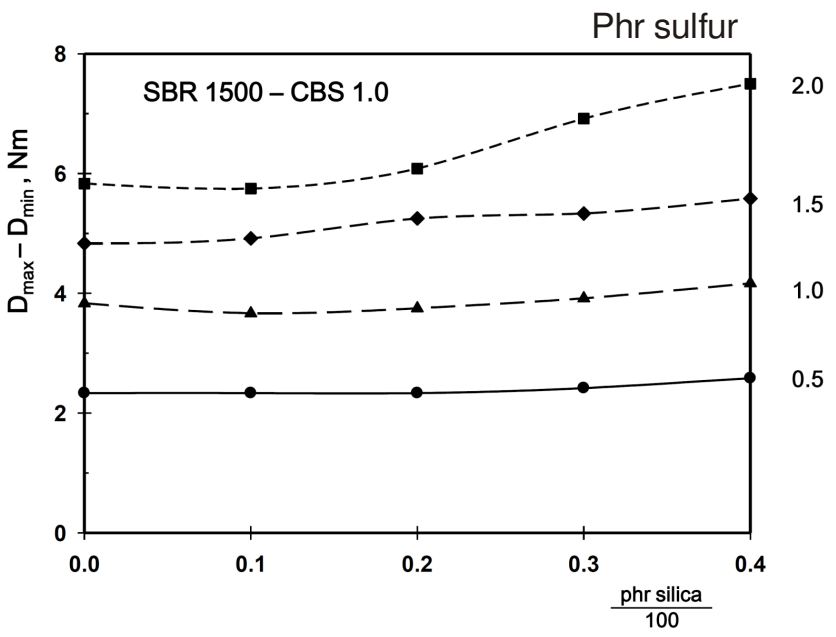

Fig. 2. $\Delta$ Torque $\left(\mathrm{D}_{\max }-\mathrm{D}_{\min }\right)$ vs. silica loading of the SBR compound with various sulfur levels at a constant accelerator (CBS) concentration. /redraw from the work of Wolff and $\operatorname{Tan}^{39}$

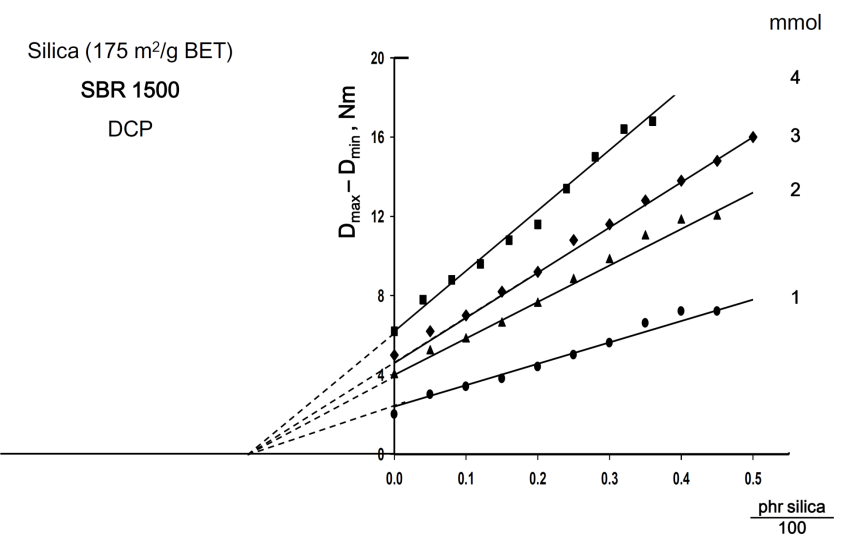

Fig. 3. $\Delta$ Torque $\left(D_{\max }-D_{\min }\right)$ vs. silica loading of SBR compound with various peroxide (DCP) concentrations/redraw from the work of Wolff and $\operatorname{Tan}^{39}$

Filler (Silica vs. CB)-Elastomer (non-polar vs. polar) interactions $^{5}$ : Fig. 4 shows plots for the normalized $\alpha_{F}$ as a function of the filler loading for CB (N110) and silica (BET $134 \mathrm{~m}^{2} / \mathrm{g}$ ) in NR (natural rubber) and NBR (acrylonitrilebutadiene rubber). In the case of CB (N110), $\alpha_{F}$ was independent of the loading over the entire range for both NR and NBR. On the other hand, in the case of silica, the $\alpha_{\mathrm{F}}$ was dependent on the filler loading. As the filler loading increased, the $\alpha_{\mathrm{F}}$ increased sharply for both silica/NR and silica/NBR compounds. The increase in the $\alpha_{F}$ value was higher in the Silica/NR compound than the silica/NBR. This is an indication of the stronger filler agglomeration of silica in NR than NBR. At a critical silica loading, the sharp increase in $\alpha_{F}$ at a higher loading is an indication of the formation of a strong silica network ${ }^{40,41}$. This critical loading is dependent on both the attractive potential and the distance between aggregates. The later onset of the sharp increase in $\alpha_{\mathrm{F}}$ for silica/NBR was attributed primarily to the reduced specific interaction factor $S_{\mathrm{f}}$ (magnitude of inter-aggregate interactions or filler-filler networking) values of the silica through increased polymer-filler interactions 
in the polar elastomer NBR. The rank of the adsorption energy is as follows: nitrile group $>$ phenyl group $>$ double bond ${ }^{42}$. The specific factor $\mathrm{S}_{\mathrm{f}}$ is defined as the adsorption energy of a given probe divided by that of an alkane (real or hypothetical) ${ }^{4}$.

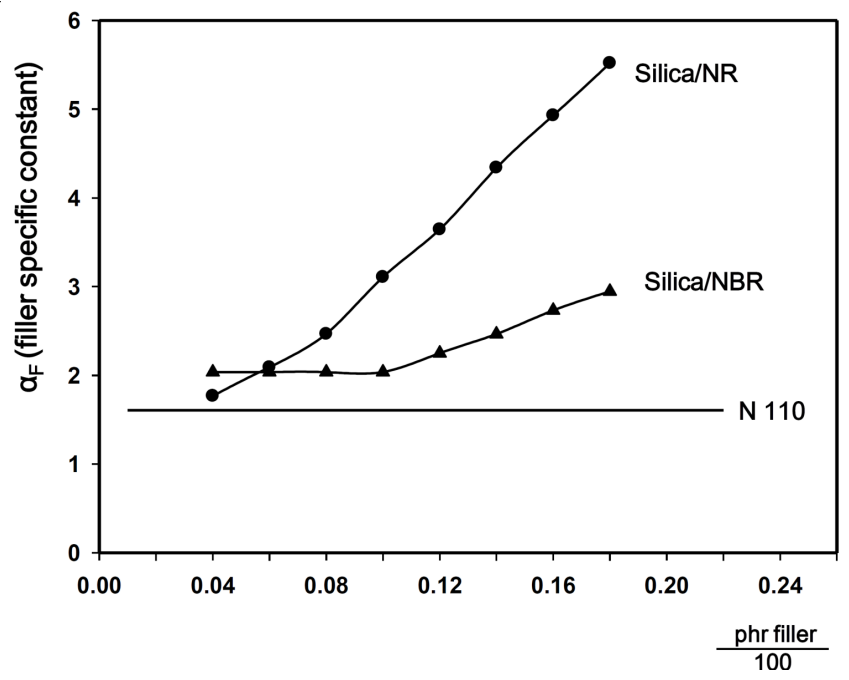

Fig. 4. Plots for the normalized $\alpha_{\mathrm{F}}$ as a function of the filler loading for $\mathrm{CB}$ (N110) and silica (BET $134 \mathrm{~m}^{2} / \mathrm{g}$ ) in NR (natural rubber) and NBR (acrylonitrile-butadiene rubber)/redraw from work of Tan et al. ${ }^{5}$

Second filler constant ' $\mathbf{A}^{\prime 43}$ : The second filler constant 'A' was obtained from measurements of the ball rebounded as a function of the filler loading. The ball rebound decreased linearly with increasing filler loading.

The second filler constant ' $\mathrm{A}$ ' can be expressed as follows:

$$
\mathrm{R}_{0}-\mathrm{R}=\mathrm{A} \cdot \frac{\mathrm{m}_{\mathrm{F}}}{\mathrm{m}_{\mathrm{P}}}
$$

where $\mathrm{R}_{0}=$ rebound of the gum, $\mathrm{R}=$ rebound of the filled vulcanizate and $\mathrm{A}=$ second filler specific constant.

Fig. 5 shows the rebound difference $\left(\mathrm{R}_{0}-\mathrm{R}\right)$ as a function of the silica loading for peroxide-cured SBR. The rebound difference increased linearly with increasing silica $\left(175 \mathrm{~m}^{2} / \mathrm{g}\right)$ loading.

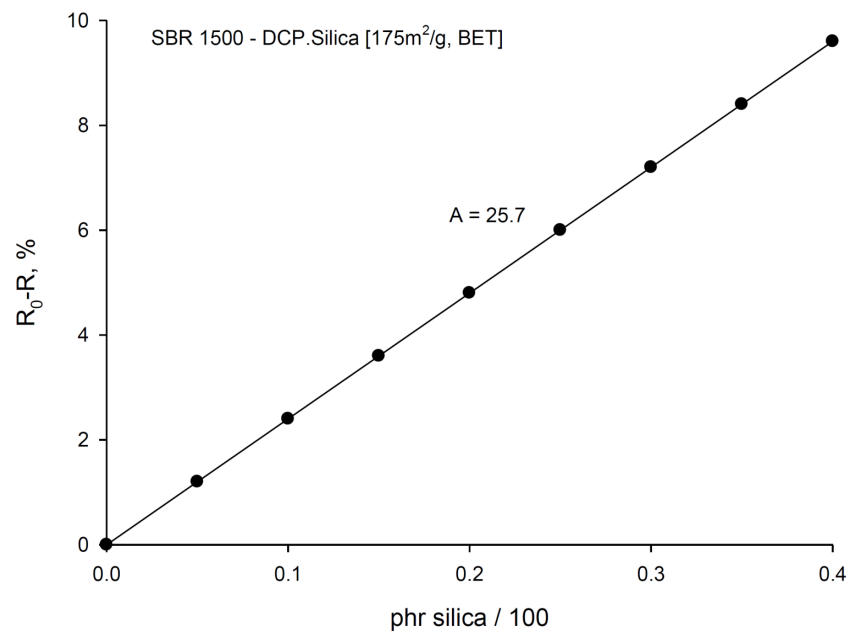

Fig. 5. Rebound difference $\left(\mathrm{R}_{0}-\mathrm{R}\right)$ vs. silica loading for peroxide-cured $\mathrm{SBR} /$ redraw from work of Wolff ${ }^{3}$

The second filler constant 'A' is also closely related to the filler surface area (Fig. 6).

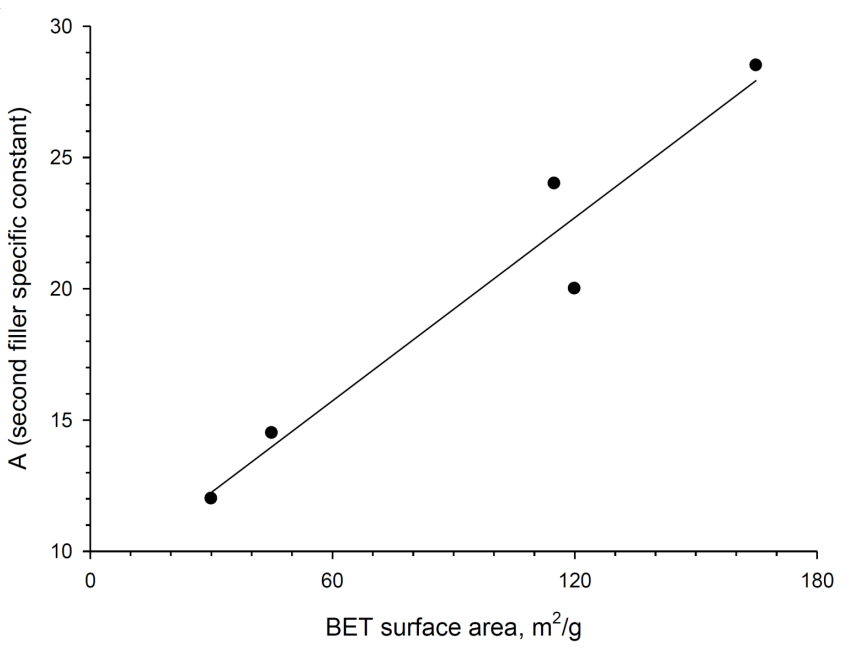

Fig. 6. Relationship between the second filler specific constant A and BET surface area for silica/redraw from work of Wolff ${ }^{3}$

Filler specific constant ' $\alpha_{\mathrm{F}}$ ' $v$ s. second filler specific constant ' $\mathbf{A}^{\prime 39}$ : The differences between silica and CB can be compared with the relationship between the filler specific constant ' $\alpha_{F}$ ' and the second filler specific constant 'A' (Fig. 7). The silica groups and $\mathrm{CB}$ groups do not overlap. $\mathrm{CB}$ is independent of $\mathrm{A}$, only dependent on $\alpha_{\mathrm{F}}$, but silica is dependent on both $\mathrm{A}$ and $\alpha_{\mathrm{F}}$. The $\alpha_{\mathrm{F}}$ for the silica group ranged from 2.86 to 7.93. The $\alpha_{\mathrm{F}}$ value of the low region silica is close to that of carbon black.

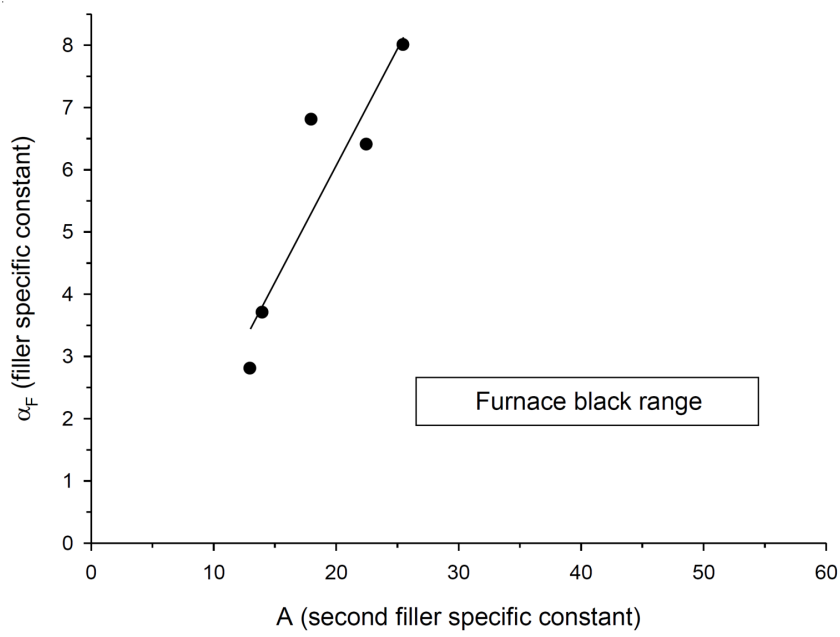

Fig. 7. Filler specific constant ' $\alpha_{\mathrm{F}}$ ' $v s$. second filler specific constant 'A' for silica and CB/redraw from report of Wolff and $\operatorname{Tan}^{3939}$

Silane modified silica: The silanization of silica causes primary changes in their reinforcing characteristics (Fig. 8). The dispersive component of the surface energy $\gamma_{\mathrm{s}}^{\mathrm{d}}$ decreases, even below the value of unmodified silica and the polar component $\gamma^{\mathrm{sp}}$ becomes negligible. This prevents the formation of a silica network through hydrogen bonds. The addition of bifunctional organosilane (TESPT) forms a covalent silicasilane-rubber network, i.e. a strong 3-dimensional network.

Fig. 9 shows the effects of silane modification on the silica surface upon $\alpha_{\mathrm{F}}$ and A. The in-rubber structure of the silica $\alpha_{\mathrm{F}}$ was reduced from 5.6 to 1.9 , which the level of $\mathrm{CB}$ as indicated in the rectangular box and the in-rubber surface area $\mathrm{A}$ was elevated from 20 to 46, which is similar to the level of CB. 


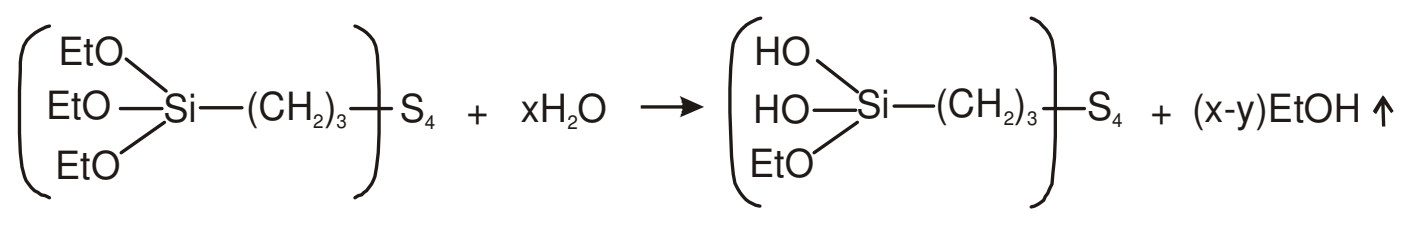

(a)

Hydrolyzed TESPT

y: unreacted alkoxy group

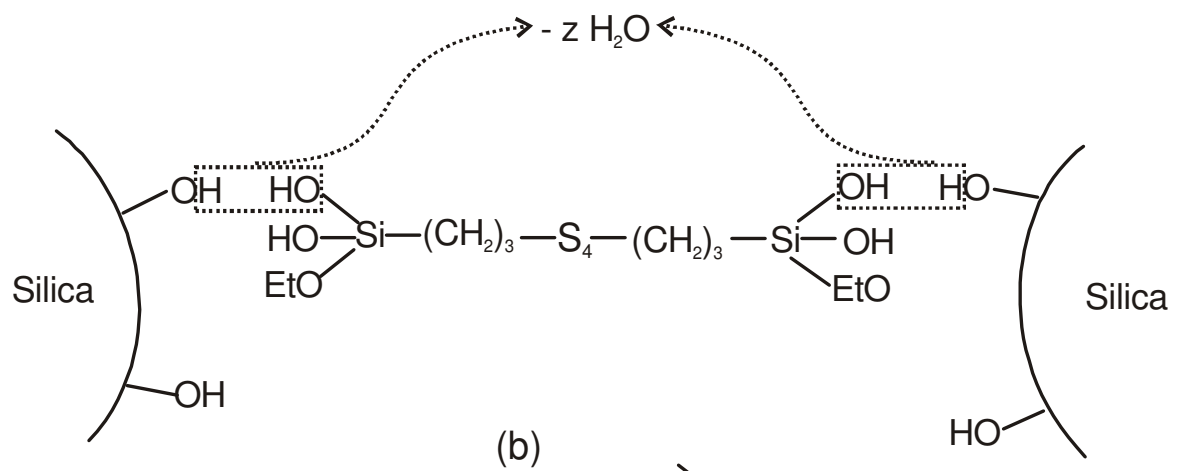

(b)
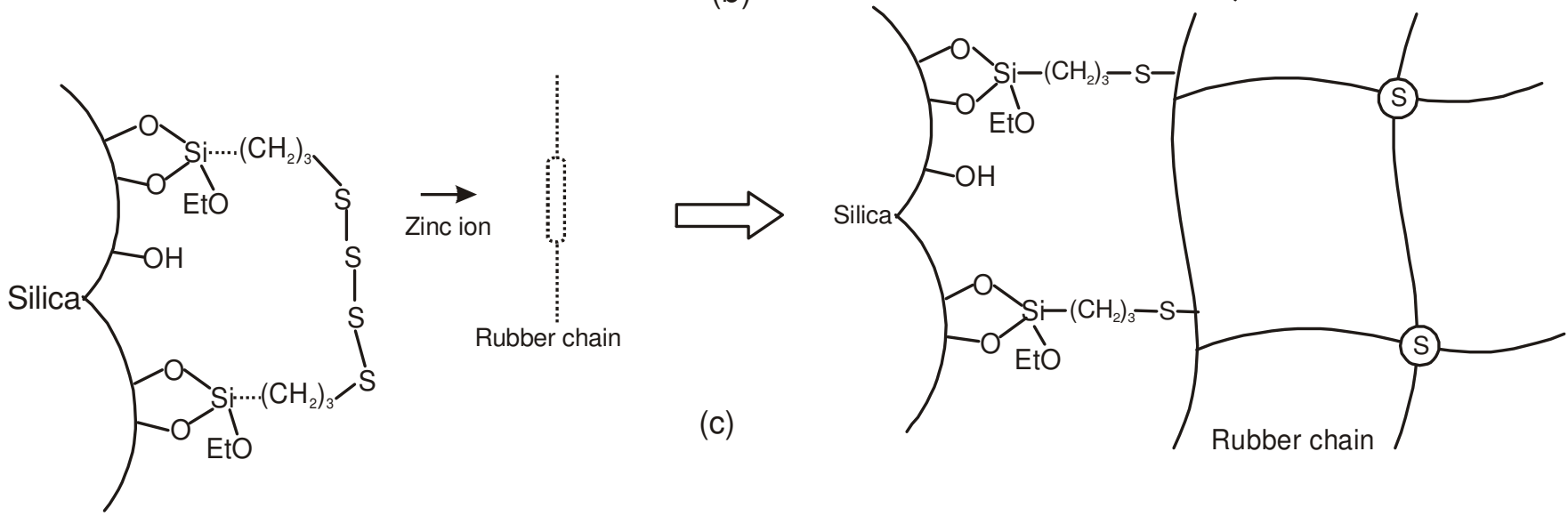

Fig. 8. Schematic diagram of (a) hydrolysis of silane, (b) condensation between hydrolyzed silane and the silica surface, (c) chemical reaction between sulfur and the rubber chain

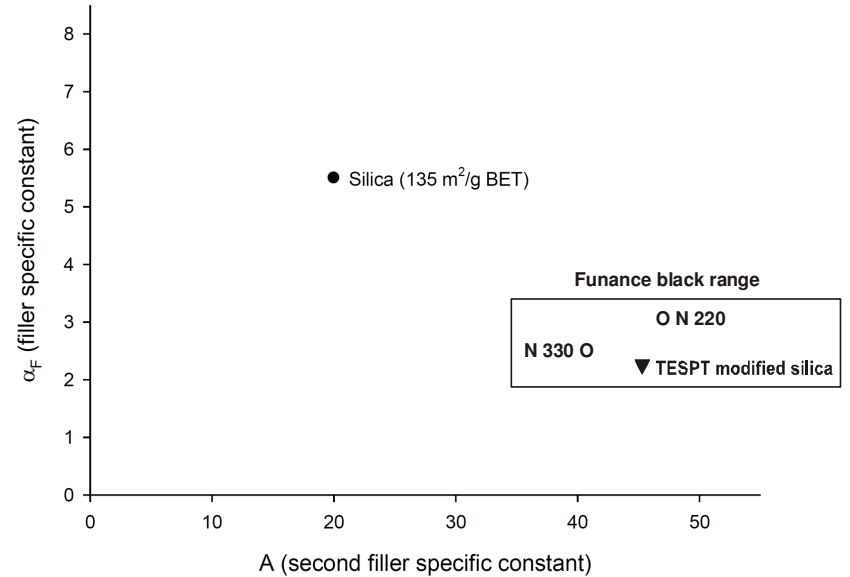

Fig. 9. Effects of silane modification on the silica surface upon $\alpha_{\mathrm{F}}$ and A/ redraw from work of Wolff ${ }^{3}$

Silica/silane loading effects on $\boldsymbol{\alpha}_{\mathrm{F}}{ }^{31,32}$ : The $\alpha_{\mathrm{F}}$ value increased with increasing silica/silane loading (silane concentration 2, 4, 6, 8, 10, $12 \%$ ) (Fig. 10). A positive $\alpha_{\mathrm{F}}$ value was observed from the compounds that contain a silane concentration $>6 \%$.

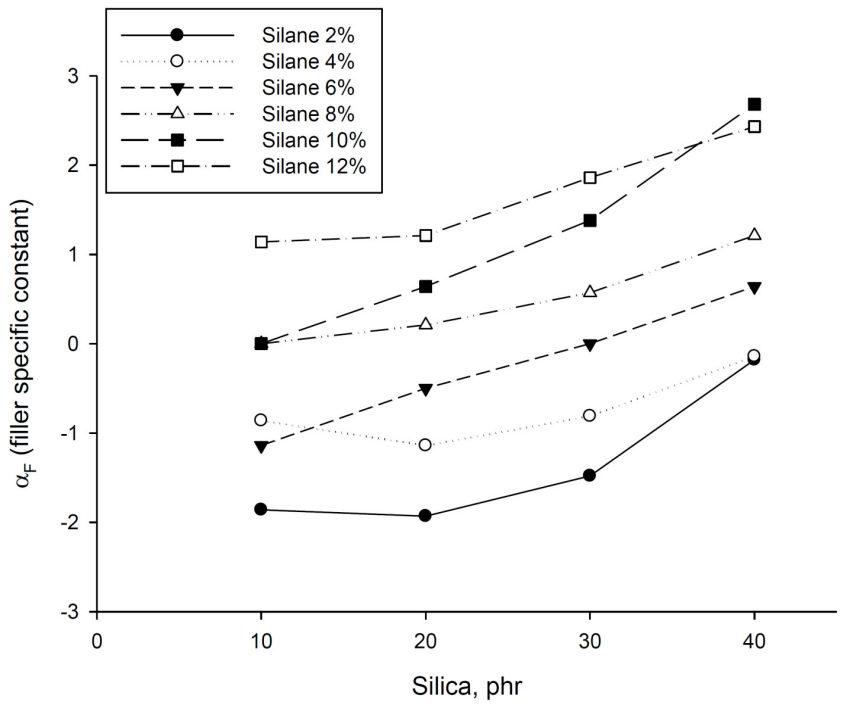

Fig. 10. Changes in $\alpha_{\mathrm{F}}$ value as a function of the silica loading upon various silane loadings $(2,4,6,8,10,12 \%) /$ redraw from work of Kim et al. ${ }^{32}$

Silane concentration effects on $\alpha_{F}$ for silica/silane compound $^{31,32}$ : Fig. 11 shows the changes in $\alpha_{F}$ value as a 
function of the silane loading upon various silica loadings (10, $20,30,40 \mathrm{phr})$. The $\alpha_{\mathrm{F}}$ value increased with increasing silane concentration. This is due mainly to the presence of sulfur atoms in TESPT, which acts as a sulfur donor ${ }^{11,25,29}$. The treatment of the silica surface with silane reduces the silica-silica interaction, which decreases the $\alpha_{\mathrm{F}}$ values $^{3}$. On the other hand, the $\alpha_{F}$ value increased with increasing silane-treated silica loading. This appears to be due mainly to the increased polymerpolymer and silica-polymer interactions ${ }^{29}$. Therefore, Wolff's theory should be re-expressed as follows (eqn. 3) ${ }^{32}$.

$$
\frac{\mathrm{D}_{\max }-\mathrm{D}_{\min }}{\mathrm{D}_{\max }^{\mathrm{o}}-\mathrm{D}_{\min }^{\mathrm{o}}}-1=\alpha_{\mathrm{C}} \frac{\mathrm{m}_{\mathrm{F}}}{\mathrm{m}_{\mathrm{P}}}
$$

where, $D_{\max }$ and $\mathrm{D}_{\min }$ are the maximum and minimum torque of the filled rubber compounds, respectively, $\mathrm{D}^{0}{ }_{\text {max }}$ and $\mathrm{D}^{0}{ }_{\text {min }}$ are the maximum and minimum torque of the polymer, respectively, $\mathrm{m}_{\mathrm{F}}$ and $\mathrm{m}_{\mathrm{P}}$ are the filler and polymer mass in the compounds, respectively. $\alpha_{\mathrm{C}}$ is a measure of the in-rubber structure of the compound, $\alpha_{C}=\alpha_{F}+\alpha_{p}+\alpha_{F P}$. $\alpha_{F}$ is a measure of the in-rubber structure of the filler-filler, $\alpha_{\mathrm{P}}$ is a measure of the in-rubber structure of the polymer-polymer and $\alpha_{\mathrm{FP}}$ is a measure of the in-rubber structure of the filler-polymer.

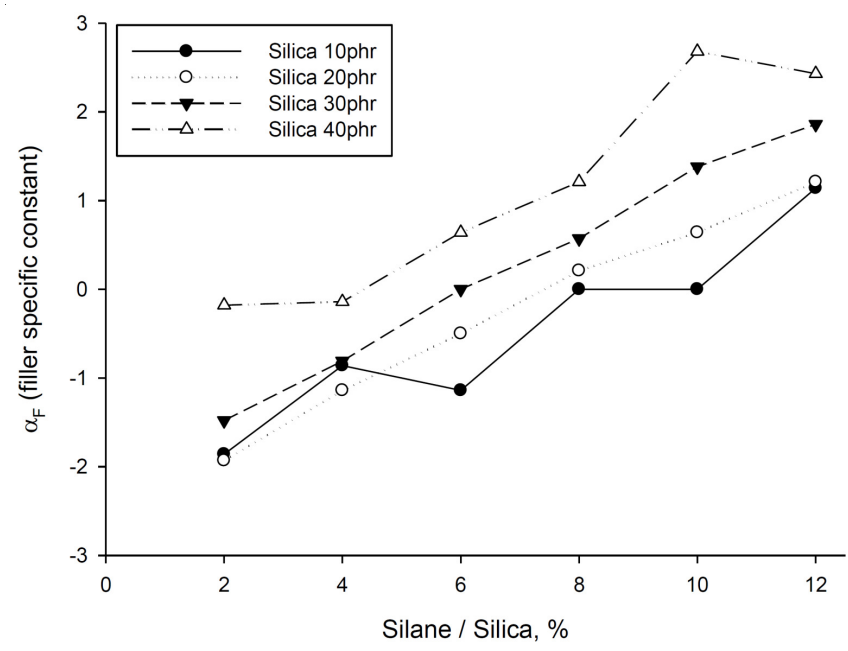

Fig. 11. Changes in $\alpha_{\mathrm{F}}$ value as a function of the silane loading upon various silica loadings $(10,20,30,40 \mathrm{phr}) /$ redraw from work of Kim et al. ${ }^{32}$

Fig. 12 gives an example of $\alpha_{\mathrm{FP}}$ compared to $\alpha_{\mathrm{F}}$ which does not have a filler-polymer interaction. Fig. 8(c) shows the chemical structure of $\alpha_{\mathrm{FP}}$.

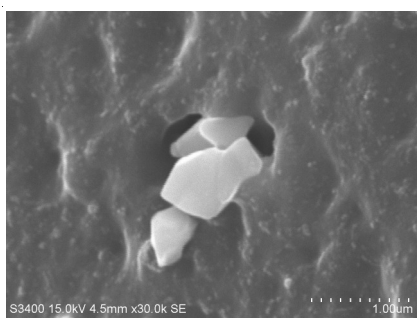

(a) without silane

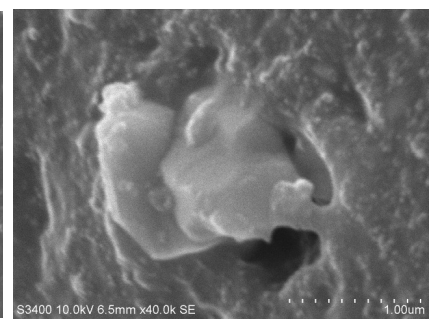

(b) with silane (TESPT)
Fig. 12. SEM image of (a) without silane, (b) with silane (TESPT) coupled on the silica surface and rubber chain $\left(\alpha_{\mathrm{FP}}\right)$

Concluding remarks: This paper reviews the Wolff's research results regarding the in-rubber structure $\left(\alpha_{\mathrm{F}}\right)$ of carbon black and silica and reported our recent research results of silane-treated silica systems. Owing to the formation of a 3-dimensional network structure in the compound via a chemical reaction of bifunctional silane with the silica surface and rubber chain, the filler network constant of silanemodified silica should be expressed by considering $\alpha_{\mathrm{P}}$ and $\alpha_{\mathrm{FP}}$ in addition to Wolff's $\alpha_{\mathrm{F}}$, i.e. $\alpha_{\mathrm{C}}=\alpha_{\mathrm{F}}+\alpha_{\mathrm{P}}+\alpha_{\mathrm{FP}}$. His interpretation of $\alpha_{\mathrm{F}}$, which focused mainly on the in-rubber filler structure, was updated by considering the network structure of the silane-treated silica system.

\section{REFERENCES}

1. S. Wolff, Kautsch. Gimmi. Kunstst., 22, 367 (1969).

2. S. Wolff, Kautsch. Gimmi. Kunstst., 23, 7 (1970).

3. S. Wolff, Rubber Chem. Technol., 69, 325 (1996).

4. S. Wolff and M.J. Wang, Rubber Chem. Technol., 65, 329 (1992).

5. E.H. Tan, S. Wolff, M. Haddeman, H.P. Grewatta and M.J. Wang, Rubber Chem. Technol., 66, 594 (1993).

6. A.R. Payne and R.E. Whittaker, Rubber Chem. Technol., 44, 440 (1971).

7. A.R. Payne, Rubber Plast. Age, 42, 963 (1961).

8. R. Rauline, EUR Patent EP0501227 (1992).

9. R. Rauline, U.S. Patent US5227425 (1993).

10. M.P. Wagner, Rubber Chem. Technol., 49, 703 (1976).

11. R.K. Gupta, E. Kennal and K.J. Kim, Polymer Nanocomposites Handbook, CRC Press, Boca Raton (2009).

12. K.J. Kim and J.L. White, Thermoplastic and Rubber Compounds, Hanser, Münch (2008).

13. A.I. Isayev, C.K. Hong and K.J. Kim, Rubber Chem. Technol., 76, 923 (2003).

14. K.J. Kim and J.L. White, J. Ind. Eng. Chem., 6, 372 (2000).

15. S.M. Kim, H.W. Cho, J.W. Kim and K.J. Kim, Elast. Compos., 45, 223 (2010).

16. K.J. Kim and J. Vanderkooi, Compos. Interf., 11, 471 (2004).

17. K.J. Kim and J. Vanderkooi, Rubber Chem. Technol., 78, 84 (2005).

18. K.J. Kim and J. Vanderkooi, J. Appl. Polym. Sci., 95, 623 (2005).

19. S.M. Kim, C.S. Nam and K.J. Kim, Appl. Chem. Eng., 22, 144 (2011).

20. C.Y. Choi, S.M. Kim, Y.H. Park, M.K. Jang, J.W. Nah and K.J. Kim, Appl. Chem. Eng., 22, 411 (2011).

21. K.J. Kim, J. Appl. Polym. Sci., 124, 2937 (2012).

22. D.T.T. Nga, J.K. Kim and K.J. Kim, Int. Polym. Process., 26, 368 (2011).

23. D.T.T. Nga, S. Lee, J.K. Kim and K.J. Kim, Compos. Interf., 18, 151 (2011).

24. D.T.T. Nga, J.K. Kim and K.J. Kim, J. Vinyl Additive Technol., 16, 254 (2010).

25. K.J. Kim and J.L. White, J. Ind. Eng. Chem., 7, 50 (2001).

26. K.J. Kim and J.L. White, J. Ind. Eng. Chem., 6, 262 (2000).

27. K.J. Kim and J. Vanderkooi, J. Ind. Eng. Chem., 8, 334 (2002).

28. K.J. Kim and J.L. White, Compos. Interf., 9, 541 (2002).

29. K.J. Kim and J. Vanderkooi, Kautsch. Gummi. Kunstst., 55, 518 (2002).

30. C. Lin and W.L. Hergenorother, A.S. Hilton, Rubber Chem. Technol., 75, 215 (2002).

31. S.M. Kim, C.Y. Choi, M.K. Jang, J.W. Nah and K.J. Kim, Elast. Compos., 47, 18 (2012)

32. S.M. Kim, M.K. Jang, C.Y. Choi, J.W. Nah and K.J. Kim, Elast. Compos., 47, 23 (2012)

33. S. Wolff, K. Burmester and E.H. Tan, Kautsch. Gummi. Kunstst., 29, 691 (1976)

34. A. Wesrlinning and S. Wolff, Kautsch. Gummi. Kunstst., 19, 470 (1966).

35. S. Wolff, Kautsch. Gummi. Kunstst., 22, 367 (1969).

36. S. Wolff, Kautsch. Gummi. Kunstst., 23, 7 (1970).

37. S. Wolff, H. Pöhnisch and P. Hoffmann, Kautsch. Gummi. Kunstst., 28, 379 (1975).

38. S. Wolff, Colloq. Int. CNRS, Bischenberg Obernai, no. 231 (1973).

39. S. Wolff and E.H. Tan, Rubber Division, American Chemical Society, New York, no. 66 (1986).

40. M.J. Wang, S. Wolff and E.H. Tan, Rubber Division, American Chemical Society, Louisville, Kentucky, no. 60 (1992).

41. E.H. Tan, Ph.D. Dissertation, University of Haute Alsace, France (1992).

42. M.J. Wang, S. Wolff and J.B. Donnet, Rubber Chem. Technol., 64, 559 (1991).

43. S. Wolff, Kautsch. Gummi. Kunstst., 27, 511 (1974) 